\title{
Immunosuppressive Agents in Multiple Sclerosis
}

\author{
Oliver Neuhaus, ${ }^{*}$ Bernd C. Kieseier, $^{\dagger}$ and Hans-Peter Hartung ${ }^{\dagger}$ \\ *Department of Neurology, Kliniken Landkreis Sigmaringen GmbH, D-72488 Sigmaringen, Germany \\ ${ }^{\dagger}$ Department of Neurology, Heinrich Heine University, D-40225 Düsseldorf, Germany
}

\begin{abstract}
Summary: Immunosuppressive agents have been used in multiple sclerosis (MS) for decades. The approval of several immunomodulatory agents against MS beginning in the 1990s, whose putative mechanisms of action appeared "more MSspecific," curtailed the importance of immunosuppressants, which made them treatment options of second choice. However, with the recent approval of mitoxantrone for treatment of patients with active forms of relapsing-remitting or secondary progressive MS and with a number of oral immunosuppressive agents being assessed in phase II and III clinical trials, a "re-
\end{abstract}

naissance" of this type of agents is currently occurring. This review provides an outline of the most important clinical studies and discusses relevant side effects of the major immunosuppressants (i.e., mitoxantrone, azathioprine, cyclophosphamide, methotrexate, mycophenolate mofetil, cladribine, and sirolimus/temsirolimus). The current knowledge of the putative mechanisms of action of these compounds is discussed. Key Words: Multiple sclerosis, immunosuppressive agents, mitoxantrone, azathioprine, cyclophosphamide, methotrexate, mycophenolate mofetil, cladribine, (tem)sirolimus.

\section{INTRODUCTION}

From the beginning of the descriptions of multiple sclerosis (MS), a major part of its pathogenesis has been ascribed to a deviation of the immune system (i.e., MS was and is still considered to be an autoimmune disorder). Thus, apart from glucocorticosteroids, immunosuppressive agents were among the very first drugs available against MS and were used off-label, but at least, in part, they were used successfully. Immunosuppressants are inhibitors of crucial components of the immune system causing generalized immune dysfunction. However, the potential beneficial effects of these therapies in MS are limited by systemic adverse effects, such as increased risk of neoplasia or infection.

More recently, two classes of immunomodulatory agents have been approved for the treatment of relapsing-remitting MS, interferon- $\beta$, and glatiramer acetate. ${ }^{1-5}$ Immunomodulators, without generally suppressing immunological properties, shift immune responses from pro-inflammatory autoimmune conditions (mediated by T-helper $(\mathrm{TH}) 1$ cytokines released from autoreactive $\mathrm{T}$ cells) toward a more beneficial anti-inflamma-

Address correspondence and reprint requests to: Hans-Peter Hartung, MD, Department of Neurology, Heinrich Heine University, Moorenstraße 5, D-40225 Düsseldorf, Germany. E-mail: hans-peter.hartung@ uni-duesseldorf.de. tory environment (mediated through $\mathrm{TH} 2$ cytokines secreted by regulatory $\mathrm{T}$ cells). These immunomodulators were thus considered first-line options in strategies to modify the disease course in MS. As a consequence, the importance of immunosuppressants declined.

More recently, however, with mitoxantrone, an immunosuppressant has been approved for treatment of active forms of relapsing-remitting and secondary progressive MS and this has brought this substance group back into the focus of therapeutic strategies of disease stages that were not that well treatable with immunomodulators. Furthermore, the "renaissance" of immunosuppressive agents is supported by a number of oral immunosuppressants currently being assessed in phase II and III clinical trials that may soon become available as the first evidence-based, oral disease-modifying drugs against MS.

Here we discuss the current knowledge of both the "classical" immunosuppressants (i.e., mitoxantrone, azathioprine, cyclophosphamide, and methotrexate) and the "newer" oral immunosuppressants (i.e., mycophenolate mofetil, cladribine, and sirolimus/temsirolimus).

\section{Mitoxantrone}

Mitoxantrone is an anti-neoplastic agent that was developed in the 1970s. It is an anthracenedione derivative related to the anthracyclins doxorubicin and daunorubicin. It interacts with topoisomerase-2, stabilizes its cleavable complex with DNA, and thus prevents the ligation 
of DNA strands and consecutively delays the cell-cycle progression. ${ }^{6}$ Mitoxantrone is used to effectively treat malignancies such as breast and advanced prostate cancer, lymphoma, and leukemia. ${ }^{7}$

Mitoxantrone was proven effective in both actively and passively induced experimental autoimmune encephalomyelitis, an animal model for MS. ${ }^{8-10}$ Ridge et al. ${ }^{8}$ observed a dose-dependent inhibitory effect as determined by clinical evaluation and histopathology in rat experimental autoimmune encephalomyelitis. Moreover, in an adoptive transfer model, encephalitogenic $\mathrm{T}$ cells treated with mitoxantrone prior to injection were no longer able to induce the disease, indicating an inhibitory effect of mitoxantrone on $\mathrm{T}$ cells. Clinical relapses were prevented or ameliorated. ${ }^{9,10}$

\section{Studies in MS}

Apart from some small open trials indicating positive effects of mitoxantrone in MS (overview by Edan et al. ${ }^{11}$ ), four controlled trials performed in different European countries substantiated its efficacy as follows:

1) In a randomized, magnetic resonance imaging (MRI)-controlled but clinically unblinded and not placebo-controlled trial in France and the United Kingdom, the effects of mitoxantrone were assessed in patients with very active MS, defined as frequent severe relapses without clinical remittance. ${ }^{12}$ Forty-two patients were included and randomized and received monthly infusions of either $20 \mathrm{mg}$ mitoxantrone (irrespective of their body surface) plus $1 \mathrm{~g}$ methylprednisolone (MP) or $1 \mathrm{~g}$ MP alone for 6 months. The primary endpoint was the percentage of patients without new active MRI lesions. At the study entry, the percentages were mitoxantrone plus MP (10\%) and MP alone (4.8\%). After 6 months, the percentages were mitoxantrone plus MP $(90 \%)$ and MP alone $(31 \%)(p<0.001)$.

2) In an Italian trial, the efficacy of mitoxantrone was assessed in 51 patients with relapsing-remitting MS. ${ }^{13}$ The patients were randomized and received either mitoxantrone $\left(8 \mathrm{mg} / \mathrm{m}^{2}\right.$ body surface) or a placebo. Clinical assessment was performed by blinded physicians. The primary endpoint was the percentage of patients with clinical progression, defined as an increase of the expanded disability status scale (EDSS) $)^{14}$ by 1 point. After 24 months of observation, 9 of 24 patients with a placebo (37\%) and 2 of 27 patients with mitoxantrone (7\%) deteriorated clinically by 1 EDSS point $(p=0.02$ ). Regarding the secondary endpoints, mitoxantrone was partially superior to the placebo.

3) A comparative double-blind trial of mitoxantrone (13 infusions of $12 \mathrm{mg} / \mathrm{m}^{2}$ body surface) versus
MP (13 infusions of $1 \mathrm{~g}$, both groups for 32 months) in 49 patients with secondary progressive MS, performed in Belgium, revealed both a significant improvement of the EDSS and a significant decrease of the total number of gadolinium-enhancing lesions in the mitoxantrone group. ${ }^{15}$

4) The largest phase III study was the Mitoxantrone in Multiple Sclerosis (MIMS) trial, leading to the approval of mitoxantrone by a number of regulatory authorities. ${ }^{16}$ The MIMS study was a randomized, placebo-controlled, investigator-blinded, multicenter trial in patients with worsening relapsing-remitting MS and secondary progressive MS. The patients ( $\mathrm{n}=$ 194) with an EDSS between 3 and 6 were randomized and divided into three groups: 1) mitoxantrone (12 $\mathrm{mg} / \mathrm{m}^{2}$ body surface), 2) mitoxantrone $\left(5 \mathrm{mg} / \mathrm{m}^{2}\right)$, and 3) placebo (methylene blue). All patients received mitoxantrone or a placebo intravenously every three months for two years. The primary study endpoint was a multivariate analysis of five different clinical parameters (change from three neurological baseline scores, including EDSS after 24 months, time to first treated relapse, and number of relapses treated with steroids). After two years, 188 patients still participated in the study. In all five parameters, the mitoxantrone $\left(12 \mathrm{mg} / \mathrm{m}^{2}\right)$ group was significantly superior compared to the other groups. Progression of disability and relapse rate were significantly reduced. This therapeutical effect was still measurable 12 months after the final infusion. In a subgroup of 110 patients, in addition to the clinical investigation, MRI assessment was performed and analyzed in a central laboratory. ${ }^{17}$ Significantly fewer patients receiving mitoxantrone $\left(12 \mathrm{mg} / \mathrm{m}^{2}\right)$ demonstrated enhancing lesions at 24 months relative to the placebo group ( $0 \%$ vs. $15.6 \% ; p=0.02$ ). The mean increase in the number of T2-weighted lesions was 0.29 in mitoxantrone $\left(12 \mathrm{mg} / \mathrm{m}^{2}\right)$ recipients and 1.94 in the placebo recipients $(p=0.03)$. In both mitoxantrone groups, a significant reduction of new lesions and a reduced burden of disease were observed.

\section{Mechanism of action}

Apart from the cytotoxic efficacy of mitoxantrone, immunosuppressive effects and even antiviral and antibiotic effects have been observed. More recently, immunomodulatory properties have been suggested, as a number of distinct immunological effects have been described. ${ }^{18-20}$ As mitoxantrone has been wellestablished for more than two decades, it is a potent immunosuppressive agent targeting proliferating immune cells. ${ }^{21-24}$ It inhibits proliferation of macrophages, $\mathrm{B}$ lymphocytes and $\mathrm{T}$ lymphocytes. ${ }^{21,23} \mathrm{Mi}-$ toxantrone has been shown to induce apoptosis of $\mathrm{B}$ lymphocytes ${ }^{25}$ and other types of antigen-presenting 
cells. ${ }^{26}$ Comparison of peripheral blood mononuclear cells obtained from MS patients, before and immediately after application of mitoxantrone, exhibited a decreased proliferation of peripheral blood mononuclear cells based on necrotic cell death, predominantly in B cells. ${ }^{27}$ Fidler et al. ${ }^{21}$ reported a decreased secretion of the pro-inflammatory cytokines interferon- $\gamma$, tumor necrosis factor- $\alpha$ and interleukin (IL)-2. In contrast, recent ex vivo analysis of the cytokine profile of immune cells obtained from patients before and during treatment with mitoxantrone revealed a decrease of IL-10 (an anti-inflammatory cytokine) expressing monocytes and a decrease of IL- $2 \mathrm{R}-\beta 1$ expressing $\mathrm{T}$ cells after six months of treatment. ${ }^{28}$ Furthermore, mitoxantrone was shown to inhibit migratory properties of immune cells. ${ }^{29}$ Still, more research is warranted to illuminate the immunological effects of mitoxantrone in MS as its specific mechanisms of action in targeting the immune system still remain widely unclear.

\section{Adverse effects}

The MIMS trial and preceding studies exhibited a generally good safety profile for mitoxantrone. ${ }^{16}$ Adverse events were rare, and they were mild to moderate. Secondary amenorrhea occurs in up to $10 \%$ of female patients treated with mitoxantrone. ${ }^{30}$ However, long-term follow-up data are still pending for final evaluation of the safety profile of mitoxantrone. To this end, a large openlabel multicenter study of mitoxantrone in 509 MS patients with a five-year observation period and a broad number of outcome measures, including the Registry to Evaluate Novantrone Effects in Worsening MS (RENEW) study is currently underway. Recent interim results of a population study representing more than 700 patient-years of mitoxantrone revealed a continued favorable benefit-risk profile but pointed out the necessity to monitor cardiac function and blood count. ${ }^{31}$

Cardiotoxicity. Treatment with mitoxantrone is restricted to a cumulative total life dose of $140 \mathrm{mg} / \mathrm{m}^{2}$ body surface. The reason for this restriction is the increased risk of irreversible congestive cardiomyopathy beyond the threshold of $140 \mathrm{mg} / \mathrm{m}^{2}$ body surface as observed in cancer patients treated with mitoxantrone. ${ }^{32,33}$ A retrospective study has investigated the risk of mitoxantroneinduced cardiotoxicity in patients with MS. ${ }^{34}$ Data obtained from 1,378 patients from three clinical trials were analyzed: 1) the MIMS trial (124 patients), ${ }^{16}$ 2) a French open multicenter trial (802 patients), ${ }^{30,35}$ and 3) a retrospective German trial (452 patients). ${ }^{36}$ The mean treatment duration was 29 months; the mean cumulative dose was $61 \mathrm{mg} / \mathrm{m}^{2}$ body surface. One hundred forty-one patients received a cumulative mitoxantrone dose of more than $100 \mathrm{mg} / \mathrm{m}^{2}$ body surface. Lethal congestive heart failure after onset of therapy with mitoxantrone devel- oped in 2 of 1378 patients. One of the two patients received a cumulative dose of $162 \mathrm{mg} / \mathrm{m}^{2}$ body surface, whereas the other patient received only one single dose of $9 \mathrm{mg} / \mathrm{m}^{2}$; for the second patient, left ventricular ejection fraction was $>50 \%$ after one year, and she died of congestive heart failure four years after treatment with mitoxantrone. Seven hundred seventy-nine patients were examined by echocardiography before and during treatment. In 17 of these patients, a reduction of the left ventricular ejection fraction below 50\% was observed. All 17 patients had received a cumulative dose of more than $100 \mathrm{mg} / \mathrm{m}^{2}$. Currently, several strategies are being pursued to circumvent the problem of mitoxantroneassociated cardiotoxicity. There are treatment approaches that give pulses of reduced doses of mitoxantrone to prolong its application. Furthermore, animal data revealed that the combination of mitoxantrone with the cardioprotector dexrazoxane may be useful to ameliorate, or even prevent, the mitoxantroneassociated cardiotoxicity. ${ }^{37-39}$ Interestingly, dexrazoxane was shown to increase the efficacy of mitoxantrone in experimental autoimmune encephalomyelitis. ${ }^{39}$ An alternative would be the development of other anthracenedione derivatives with lower cardiotoxicity. ${ }^{40}$

Therapy-related acute leukemia. Mitoxantrone and other topoisomerase-2 inhibitors have been reported to induce acute leukemia. In the retrospective study with 1392 MS patients previously mentioned, one case was observed $(0.07 \%) .^{41}$ Several additional case reports have been published. ${ }^{4-52}$ Retrospectively, a relative risk of $0.21 \%$ was estimated. ${ }^{48}$ Thus, it is strongly recommended that monitoring blood cell counts should be continued for at least five years after discontinuation of therapy.

\section{Azathioprine}

Azathioprine is a purine analogue that is metabolized rapidly to the cytotoxic and immunosuppressant derivatives 6-mercaptopurine and thioinosine acid, the latter competing with DNA nucleotides. It is widely used in organ transplantation and in autoimmune disorders, ${ }^{53}$ and is considered a second-line drug in MS.

By far the largest prospective randomized, doubleblind, placebo-controlled trial of azathioprine in MS was the British-Dutch trial published in $1988 .^{54}$ Three hundred fifty-four patients with either relapsing-remitting or secondary progressive MS were subjected to either azathioprine ( $2.5 \mathrm{mg}$ per $\mathrm{kg}$ per day) or to a placebo. The only significant outcome measure was the slower progression in the azathioprine-treated group when using the so-called ambulation index. For the EDSS, there was a trend in favor of azathioprine. In the early 1990s, five previously published randomized, double-blind, placebocontrolled trials, including the British-Dutch study, were analyzed in a meta-analysis indicating that azathioprine 
reduces the relapse rate in MS. ${ }^{55}$ Interestingly, the probability of being free of relapses after two years of treatment with azathioprine, as assessed in this meta-analysis, appeared comparable to the efficacy of interferon- $\beta$ or glatiramer acetate, ${ }^{56}$ as assessed in the respective pivotal trials. ${ }^{1,2,4}$ However, the meta-analysis did not reveal an impact on the progression of disability. ${ }^{55}$ Due to the loss of patent protection of azathioprine, more recent controlled trials have not been performed.

Azathioprine depresses both cellular and humoral immunity. It mainly targets activation, proliferation, and differentiation of both $\mathrm{T}$ and $\mathrm{B}$ lymphocytes by competition of its metabolites with DNA nucleotides. So far, further specific immunomodulatory properties have not been reported. The major concern of azathioprine is the increased risk of non-Hodgkin's lymphoma or skin cancer after long-term use (i.e., after approximately 10 years) ${ }^{57}$ However, this risk was not confirmed in a casecontrolled study. ${ }^{58}$

\section{Cyclophosphamide}

Cyclophosphamide is an alkylating agent of the nitrogen mustard group; its active metabolites (by hepatic cytochrome p-450) induces DNA string breaks. Although used off-label, cyclophosphamide plays a role as an escalating immunotherapy option in severe forms of MS. ${ }^{59}$ The only prospective, double-blind, placebo-controlled, randomized trial was the Canadian co-operative trial with 168 patients with secondary progressive MS that unfortunately revealed no beneficial effects. ${ }^{60} \mathrm{How}-$ ever, in some controlled but unblinded trials, cyclophosphamide exhibited at least some effects in patients with chronic MS. ${ }^{61-63}$ Taken together, the available data do not allow definite conclusion on the efficacy of cyclophosphamide in MS. ${ }^{64}$

Cyclophosphamide possesses strong cytotoxic and immunosuppressive properties. Apart from strong immunosuppression, cyclophosphamide can also exert immunomodulatory effects shifting immune responses from TH1 toward TH2 by an unknown mechanism. ${ }^{65}$ Cyclophosphamide can cause several side effects, such as alopecia, nausea, vomiting, hemorrhagic cystitis, leukopenia, myocarditis, infertility, and pulmonary interstitial fibrosis.

\section{Methotrexate}

Methotrexate is an antimetabolite that interferes with DNA synthesis by inhibiting dihydrofolate reductase and thus thymidine biosynthesis. It reduces 1-carbon transfers into purines. Methotrexate was shown in one placebo-controlled study to convey some therapeutic benefit in progressive forms of MS. ${ }^{66}$ Sixty patients were treated with methotrexate ( $7.5 \mathrm{mg}$ weekly) or with a placebo for 2 years. Methotrexate significantly reduced sustained worsening, as assessed by a composite measure of disability using the EDSS, the ambulation index, and two tests of arm function. The mechanisms of action of methotrexate in autoimmune diseases are elusive. Toxicity of methotrexate is minimal, if treatment is paralleled by folate substitution.

\section{Mycophenolate mofetil}

Mycophenolate mofetil belongs to the antimetabolite drug class and is a pro-drug of its active metabolite mycophenolic acid. Small open-label trials in progressive MS suggest some efficacy, and its administration appeared well tolerated. ${ }^{67,68}$ Interestingly, in an openlabel trial, the combination of mycophenolate mofetil with interferon- $\beta 1$ a exhibited superior efficacy as compared to interferon- $\beta 1$ a alone. ${ }^{69}$ Controlled and larger studies are warranted. The precise immunological mechanism of action of mycophenolate mofetil remains elusive. Its adverse event profile is generally good.

\section{Cladribine}

Cladribine is an adenosine deaminase-resistant nucleoside analog with selective lymphotoxic specificity. The phosphorylated active triphosphate deoxynucleotide accumulates in lymphocytes and monocytes and causes DNA damage followed by cell death. ${ }^{70,71}$ The efficacy of cladribine in MS has been, and is being, assessed in both subcutaneous and orally administered formulations. Smaller placebo-controlled trials of subcutaneously administered cladribine in chronic progressive and relapsing-remitting MS revealed promising results, not only clinically but also in MRI parameters. ${ }^{72-74}$ However, a double-blind, placebo-controlled phase III study of subcutaneously administered cladribine in 159 patients with secondary and primary progressive MS unexpectedly failed to exhibit significant clinical and MRI benefits after one year. ${ }^{75}$ As cladribine also exists in an oral formulation and as pilot trials also have provided encouraging data, ${ }^{76}$ a large randomized, double-blind, placebocontrolled phase III trial, including 1,290 patients with active inflammatory relapsing-remitting MS has recently been initiated.

Due to its selective lymphotoxicity with long-lasting activity, cladribine is believed to be of use in autoimmune conditions. In the phase III trial of subcutaneously administered cladribine in progressive MS, the major adverse events were upper respiratory tract infections, muscle weakness, and injection site reactions. ${ }^{75}$

\section{Sirolimus and temsirolimus}

Sirolimus (rapamycin-derived from the bacterium Streptomyces hygroscopius) and its orally better absorbable synthetic derivative temsirolimus (CCI-779) are potent antiproliferative agents. Sirolimus is currently being tested in an open-label trial in relapsing-remitting MS. The results of a phase II placebo-controlled trial of temsirolimus in MS are already available. Assessing three different doses of temsirolimus against a placebo in 296 
Table 1. Dosages and Application Modes of the Immunosuppressants

\begin{tabular}{ll}
\hline \multicolumn{1}{c}{ Agent } & \multicolumn{1}{c}{ Recommended dose/route/frequency } \\
\hline Mitoxantrone & $12 \mathrm{mg} / \mathrm{m}^{2}$ body surface (i.v.) every $3 \mathrm{months}$ (MIMS trial regimen); $20 \mathrm{mg}$ monthly \\
& (i.v.) for 6 months (French regimen) \\
Azathioprine & $2-3 \mathrm{mg}$ per kg body weight (orally) per day \\
Cyclophosphamide & $400-1000 \mathrm{mg}$ (i.v. or orally) at various frequencies \\
Methotrexate & $7.5 \mathrm{mg}$ (orally) weekly \\
Mycophenolate mofetil & $2 \mathrm{~g}$ (orally) per day \\
Cladribine & $0.875 \mathrm{mg} / \mathrm{kg} /$ cycle (orally) over a course of 5 days per month, $2-4$ cycles per year \\
Temsirolimus & (design of current trial) \\
\hline
\end{tabular}

MIMS, Mitoxantrone in Multiple Sclerosis trial.

patients with relapsing-remitting and active secondary progressive MS revealed that the highest dose exhibited significant effects on the relapse rate and on MRI parameters. ${ }^{77}$ The decision as to whether phase III trials will occur is still pending.

Sirolimus and temsirolimus form a complex with the intracellular protein FKBP12 that blocks the activation of a kinase cascade that is crucial for cell-cycle progression. The agents thus prevent cell division in new cells, such as in proliferating $\mathrm{T}$ and $\mathrm{B}$ lymphocytes. ${ }^{78}$ A major adverse effect of sirolimus is drug-induced hyperlipidemia. Temsirolimus has been shown to induce menstrual dysfunction, mouth ulceration, hyperlipidemia, and rashes.

\section{Clinical aspects of immunosuppressants in MS}

The dosages and application modes of the discussed immunosuppressants are shown in Table 1.

Mitoxantrone. Several national and international medical advisory boards to MS societies recommend the use of mitoxantrone in patients with relapsing-remitting MS with frequent relapses and incomplete remissions and with secondary progressive MS with rapid progression (by at least one EDSS point per year).

Azathioprine. This drug may be considered in patients with relapsing-remitting MS who do not tolerate parenterally administered drugs.

Cyclophosphamide. This drug should be considered for treatment of patients with rapidly progressive disease who do not respond to less toxic alternatives. ${ }^{59,79}$

Low-dose methotrexate. This drug may serve as an alternative, practically nontoxic, immunosuppressive treatment when other agents have exhibited intolerable toxicity.

Mycophenolate mofetil, cladribine, and sirolimus/ temsirolimus. Before these drugs can be recommended for use in MS, the results of current or upcoming phase III clinical trials are being awaited.

\section{Practical guidelines}

Due to the increased risk of infections, patients treated with immunosuppressants should not receive vital vac- cines. Before onset of therapy a number of laboratory examinations are recommended including a pregnancy test (immunosuppressive agents are contraindicated during pregnancy and nursing), a chest X-ray, electrocardiography, and echocardiography with quantitative assessment of the left ventricular ejection fraction (in patients to be treated with mitoxantrone). Due to the risk of infertility, male patients should be offered the opportunity to cryopreserve their sperm. In accordance with respective laboratory results, dose adjustments may be necessary. Anti-emetic protection may be helpful.

\section{CONCLUSIONS}

For treatment of MS, immunosuppressive drugs have been used off-label for decades. Approval of immunomodulatory agents in the mid-1990s shifted the market toward interferon- $\beta$ and glatiramer acetate. However, worsening forms of MS often could not be treated satisfactorily with these new therapeutics. Thus, the approval of mitoxantrone made immunosuppressants return as a focus of interest. However, one major drawback of mitoxantrone remains its doselimiting, cumulative cardiotoxicity. The use of other "classical" immunosuppressive agents, such as azathioprine or cyclophosphamide, may provide further benefit in selected patients, although the level of evidence of their efficacy will realistically not be increased based on their loss of patent protection impeding newly designed controlled trials. At minimum, their adverse event profile is well-established and can be considered when planning an immunosuppressive strategy. In contrast, the "newer" immunosuppressants still have to prove their efficacy in the current or upcoming trials, and their adverse event profile in MS will also have to be established only with long-term post-marketing experience.

In conclusion, "classical" and potentially "newer" immunosuppressants contribute to control inflammation and relapses in MS. However, they do not prevent neurodegeneration and its clinical counterpart, the progres- 
sion of irreversible disability. ${ }^{80}$ Thus, major efforts must be made to develop treatment strategies beyond the nonspecific suppression of the immune system.

\section{REFERENCES}

1. The IFNB Multiple Sclerosis Study Group. Interferon beta-1b is effective in relapsing-remitting multiple sclerosis: I. Clinical results of a multicenter, randomized, double-blind, placebo-controlled trial. Neurology 1993;43:655-661.

2. Jacobs LD, Cookfair DL, Rudick RA, et al. Intramuscular interferon beta-1a for disease progression in exacerbating-remitting multiple sclerosis. The Multiple Sclerosis Collaborative Research Group (MSCRG). Ann Neurol 1996;39:285-294.

3. PRISMS (Prevention of Relapses and Disability by Interferon beta-1a Subcutaneously in Multiple Sclerosis) Study Group. Randomised double-blind placebo-controlled study of interferon beta-1a in relapsing/remitting multiple sclerosis. Lancet 1998;352: $1498-1504$

4. Johnson KP, Brooks BR, Cohen JA, et al. Copolymer 1 reduces relapse rate and improves disability in relapsing-remitting multiple sclerosis: results of a phase III multicenter, double-blind, placebocontrolled trial. The Copolymer 1 Multiple Sclerosis Study Group. Neurology 1995;45:1268-1276.

5. Kieseier BC, Hartung HP. Current disease-modifying therapies in multiple sclerosis. Semin Neurol 2003;23:133-145.

6. Smith IE. Mitoxantrone (Novantrone): a review of experimental and early clinical studies. Cancer Treat Rev 1983;10:103-115.

7. Shenkenberg TD, von Hoff D. Mitoxantrone: a new anticancer drug with significant clinical activity. Ann Intern Med 1986;105: 67-81.

8. Ridge SC, Sloboda AE, McReynolds RA, Levine S, Oronsky AL, Kerwar SS. Suppression of experimental allergic encephalomyelitis by mitoxantrone. Clin Immunol Immunopathol 1985;35:35-42.

9. Levine S, Saltzman A. Regional suppression, therapy after onset and prevention of relapses in experimental allergic encephalomyelitis by mitoxantrone. J Neuroimmunol 1986;13:175-181.

10. Lublin FD, Lasvasa M, Viti C, Knobler RL. Suppression of acute and relapsing experimental allergic encephalomyelitis with mitoxantrone. Clin Immunol Immunopathol 1987;45:122-128.

11. Edan G, Morrissey SP, Hartung HP. Use of mitoxantrone to treat multiple sclerosis. In: Cohen JA, Rudick RA, eds. Multiple sclerosis therapeutics. London, New York: Martin Dunitz, 2003:403426.

12. Edan G, Miller D, Clanet M, et al. Therapeutic effect of mitoxantrone combined with methylprednisolone in multiple sclerosis: a randomised multicentre study of active disease using MRI and clinical criteria. J Neurol Neurosurg Psychiatry 1997;62:112-118.

13. Millefiorini E, Gasperini C, Pozzilli C, et al. Randomized placebocontrolled trial of mitoxantrone in relapsing-remitting multiple sclerosis: 24-month clinical and MRI outcome. J Neurol 1997;244: 153-159.

14. Kurtzke JF. Rating neurological impairment in multiple sclerosis: an expanded disability status scale (EDSS). Neurology 1983;33: $1444-1452$.

15. Van de Wyngaert FA, Beguin C, D'Hooge MB, et al. A doubleblind clinical trial of mitoxantrone versus methylprednisolone in relapsing, secondary progressive multiple sclerosis. Acta Neurol Belg 2001;101:210-216.

16. Hartung HP, Gonsette R, König N, et al. A placebo-controlled, double-blind, randomised, multicentre trial of mitoxantrone in progressive multiple sclerosis. Lancet 2002;360:2018-2025.

17. Krapf H, Morrissey SP, Zenker O, et al. Effect of mitoxantrone on MRI in progressive MS: results of the MIMS trial. Neurology 2005;65:690-695.

18. Jain KK. Evaluation of mitoxantrone for the treatment of multiple sclerosis. Exp Opin Invest Drugs 2000;9:1139-1149.

19. Stüve O, Cree BC, von Büdingen HC, et al. Approved and future pharmacotherapy for multiple sclerosis. Neurologist 2002;8:290 301.

20. Neuhaus O, Kieseier BC, Hartung HP. Therapeutic role of mitoxantrone in multiple sclerosis. Pharmacol Ther 2006;109:198-209.
21. Fidler JM, de Joy SQ, Gibbons JJ. Selective immunomodulation by the antineoplastic agent mitoxantrone. I. Suppression of B lymphocyte function. J Immunol 1986;137:727-732.

22. Fidler JM, de Joy SQ, Smith FR, Gibbons JJ. Selective immunomodulation by the antineoplastic agent mitoxantrone. II. Nonspecific adherent suppressor cells derived from mitoxantrone treated mice. J Immunol 1986;136:2747-2754.

23. Mauch E, Kornhuber HH, Krapf H, Fetzer U, Laufen H. Treatment of multiple sclerosis with mitoxantrone. Eur Arch Psychiatry Clin Neurosci 1992;242:96-102.

24. Gbadamosi J, Buhmann C, Tessmer W, Moench A, Haag F, Heesen C. Effects of mitoxantrone on multiple sclerosis patients' lymphocyte subpopulations and production of immunoglobulin, TNF-alpha and IL-10. Eur Neurol 2003;49:137-141.

25. Bellosillo B, Colomer D, Pons G, Gil J. Mitoxantrone, a topoisomerase II inhibitor, induces apoptosis of B-chronic lymphocytic leukaemia cells. Br J Haematol 1998;100:142-146.

26. Neuhaus O, Wiendl H, Kieseier BC, et al. Multiple sclerosis: mitoxantrone promotes differential effects on immunocompetent cells in vitro. J Neuroimmunol 2005;168:128-137.

27. Chan A, Weilbach FX, Toyka KV, Gold R. Mitoxantrone induces cell death in peripheral blood leucocytes of multiple sclerosis patients. Clin Exp Immunol 2005;139:152-158.

28. Khoury SJ, Bharanidharan P, Bourcier K, Cook SL, Stazzone L, Weiner HL. Immunologic effects of mitoxantrone therapy in patients with multiple sclerosis. Neurology 2002;58 (supplement 3): A245-A246 (abstract).

29. Kopadze T, Dehmel T, Hartung HP, Stuve O, Kieseier BC. Inhibition by mitoxantrone of in vitro migration of immunocompetent cells: a possible mechanism for therapeutic efficacy in the treatment of multiple sclerosis. Arch Neurol 2007;63:1572-1578.

30. Edan G, Brochet B, Clanet M, et al. Safety profile of mitoxantrone in a cohort of 802 multiple sclerosis patients: a 4 year mean follow-up study. Neurology 2004;62(supplement 5):A493 (abstract).

31. Rivera V, Al-Sabbagh A, Bennett R, et al. Ongoing evaluation of the safety and tolerability of mitoxantrone in worsening multiple sclerosis: the RENEW study. Neurology 2007;68 (supplement 1): A275 (abstract).

32. De Castro S, Cartoni D, Millefiorini E, et al. Noninvasive assessment of mitoxantrone cardiotoxicity in relapsing-remitting multiple sclerosis. J Clin Pharmacol 1995;35:627-632.

33. Gonsette RE. Mitoxantrone immunotherapy in multiple sclerosis. Mult Scler 1996;1:329-332.

34. Ghalie RG, Edan G, Laurent M, et al. Cardiac adverse effects associated with mitoxantrone (Novantrone) therapy in patients with MS. Neurology 2002;59:909-913.

35. Edan G, Brochet B, Clanet M, et al. Safety profile of mitoxantrone in a cohort of 800 multiple sclerosis patients. Mult Scler 2001;7 (supplement 1):S14 (abstract).

36. Mauch E, Eisenman S, Hahn A, Zenker O, Rubin A, Ghalie R. Mitoxantrone in the treatment of patients with multiple sclerosis: a large single center experience. Mult Scler 1999;5(supplement 1): P366 (abstract).

37. Herman EH, Zhang J, Rifai N, et al. The use of serum levels of cardiac troponin $\mathrm{T}$ to compare the protective activity of dexrazoxane against doxorubicin- and mitoxantrone-induced cardiotoxicity. Cancer Chemother Pharmacol 2001;48:297-304.

38. Bernitsas E, Wei W, Mikol DD. Suppression of mitoxantrone cardiotoxicity in multiple sclerosis patients by dexrazoxane. Ann Neurol 2006;59:206-209.

39. Weilbach FX, Chan A, Toyka KV, Gold R. The cardioprotector dexrazoxane augments therapeutic efficacy of mitoxantrone in experimental autoimmune encephalomyelitis. Clin Exp Immunol 2004;135:49-55.

40. Gonsette RE. Pixantrone (BBR2778): a new immunosuppressant in multiple sclerosis with a low cardiotoxicity. J Neurol Sci 2004; 223:81-86.

41. Ghalie RG, Mauch E, Edan G, et al. A study of therapy-related acute leukaemia after mitoxantrone therapy for multiple sclerosis. Mult Scler 2002;8:441-445.

42. Vicari AM, Ciceri F, Folli F, et al. Acute promyelocytic leukemia 
following mitoxantrone as single agent for the treatment of multiple sclerosis. Leukemia 1998;12:441-442.

43. Brassat D, Recher C, Waubant E, et al. Therapy-related acute myeloblastic leukemia after mitoxantrone treatment in a patient with MS. Neurology 2002;59:954-955.

44. Heesen C, Bruegmann M, Gbadamosi J, Koch E, Monch A, Buhmann C. Therapy-related acute myelogenous leukaemia (t-AML) in a patient with multiple sclerosis treated with mitoxantrone. Mult Scler 2003;9:213-214.

45. Jaster JH, Niell HB, Dohan FCJ, Smith TW. Therapy-related acute myeloblastic leukemia after mitoxantrone treatment in a patient with MS. Neurology 2003;60:1399-1400.

46. Cattaneo C, Almici C, Borlenghi E, Motta M, Rossi G. A case of acute promyelocytic leukaemia following mitoxantrone treatment of multiple sclerosis. Leukemia 2003;17:985-986.

47. Mogenet I, Simiand-Erdociain E, Canonge JM, Pris J. Acute myelogenous leukemia following mitoxantrone treatment for multiple sclerosis. Ann Pharmacother 2003;37:747-748.

48. Voltz R, Starck M, Zingler V, Strupp M, Kolb HJ. Mitoxantrone therapy in multiple sclerosis and acute leukaemia: a case report out of 644 treated patients. Mult Scler 2004;10:472-474.

49. Arruda WO, Montu MB, de Oliveira MdS, Ramina R. Acute myeloid leukaemia induced by mitoxantrone: case report. Arq Neuropsiquiatr 2005;63:327-329.

50. Nollet S, Berger E, Deconinck E, Baldauf E, Rumbach L. Acute leukaemia in two multiple sclerosis patients treated with mitoxantrone. Rev Neurol (Paris) 2006;162:195-199.

51. Ledda A, Caocci G, Spinicci G, Cocco E, Mamusa E, Nasa GL. Two new cases of acute promyelocytic leukemia following mitoxantrone treatment in patients with multiple sclerosis. Leukemia 2006;20:2217-2218.

52. Cartwright MS, Jeffery DR, Lewis ZT, Koty PP, Stewart WT, Molnar I. Mitoxantrone for multiple sclerosis causing acute lymphoblastic leukemia. Neurology 2007;68:1630-1631.

53. Hong JC, Kahan BD. Immunosuppressive agents in organ transplantation: past, present, and future. Semin Nephrol 2000;20:108125.

54. British and Dutch Multiple Sclerosis Azathioprine Trial Group. Double-masked trial of azathioprine in multiple sclerosis. Lancet 1988: 179-183.

55. Yudkin PL, Ellison GW, Ghezzi A, et al. Overview of azathioprine treatment in multiple sclerosis. Lancet 1991;338:1051-1055.

56. Palace J, Rothwell P. New treatments and azathioprine in multiple sclerosis. Lancet 1997;350:261.

57. Lhermitte F, Marteau R, Roullet E. Not so benign long-term immunosuppression in multiple sclerosis. Lancet 1984;1(8371):276277.

58. Confavreux C, Saddier P, Grimaud J, Moreau T, Adeleine P, Aimard G. Risk of cancer from azathioprine therapy in multiple sclerosis: a case-control study. Neurology 1996;46:1607-1612.

59. Multiple Sclerosis Therapy Consensus Group. Escalating immunotherapy of multiple sclerosis. New aspects and practical application. J Neurol 2004;251:1329-1339.

60. The Canadian Cooperative Multiple Sclerosis Study Group. The Canadian cooperative trial of cyclophosphamide and plasma exchange in progressive multiple sclerosis. Lancet 1991;337:441446.

61. Hauser S, Dawson D, Lehrich J, et al. Intensive immunosuppression in progressive multiple sclerosis: a randomized, three-arm study of high-dose intravenous cyclophosphamide, plasma exchange, and ACTH. N Engl J Med 1983;308:173-180.
62. Goodkin DE, Plencner S, Palmer-Saxerud J, Teetzen M, Hertsgaard D. Cyclophosphamide in chronic progressive multiple sclerosis: maintenance vs nonmaintenance therapy. Arch Neurol 1987; 44:823-827.

63. Weiner HL, Mackin GA, Orav EJ, et al. Intermittent cyclophosphamide pulse therapy in progressive multiple sclerosis: final report of the Northeast Cooperative Multiple Sclerosis Treatment Group. Neurology 1993;43:910-918.

64. La Mantia L, Milanese C, D'Amico R, Mascoli N, WeinstockGuttman B. Cyclophosphamide in progressive multiple sclerosis: systematic review and meta-analysis of randomized trials. In: Columbus F, ed. Treatment and management of multiple sclerosis. Hauppauge, NY: Nova Science Publishers; 2005:33-48.

65. Weiner HL, Cohen JA. Treatment of multiple sclerosis with cyclophosphamide: critical review of clinical and immunologic effects. Mult Scler 2002;8:142-154

66. Goodkin DE, Rudick RA, VanderBrug-Medendorp S, et al. Lowdose $(7.5 \mathrm{mg})$ oral methotrexate reduces the rate of pregression in chronic preogressive multiple sclerosis. Ann Neurol 1995;37:3040.

67. Ahrens N, Salama A, Haas J. Mycophenolate mofetil in the treatment of refractory multiple sclerosis. J Neurol 2001;248:713-714.

68. Frohman EM, Brannon K, Racke MK, et al. Mycophenolate mofetil in multiple sclerosis. Clin Neuropharmacol 2004;27:8083.

69. Vermersch P, Waucquier N, Michelin E, et al. Combination of IFNbeta-1a (Avonex) and mycophenolate mofetil (Cellcept) in multiple sclerosis. Eur J Neurol 2007;14:85-89.

70. Beutler E. Cladribine (2-chlorodeoxyadenosine). Lancet 1992;340: 952-956.

71. Sipe JC. Cladribine for multiple sclerosis: review and current status. Exp Rev Neurotherapeutics 2005;5:721-727.

72. Sipe JC, Romine JS, Koziol JA, et al. Cladribine in treatment of chronic progressive multiple sclerosis. Lancet 1994;344:9-13.

73. Beutler E, Sipe JC, Romine JS, et al. The treatment of chronic progressive multiple sclerosis with cladribine. Proc Natl Acad Sci U S A 1996;93:1716-1720.

74. Romine JS, Sipe JC, Koziol JA, et al. A double-blind, placebocontrolled, randomized trial of cladribine in relapsing-remitting multiple sclerosis. Proc Assoc Am Physicians 1999;111:35-44.

75. Rice GP, Filippi M, Comi G. Cladribine and progressive MS: clinical and MRI outcomes of a multicenter controlled trial. Cladribine MRI Study Group. Neurology 2000;54:1145-1155.

76. Brousil JA, Roberts RJ, Schlein AL. Cladribine: an investigational immunomodulatory agent for multiple sclerosis. Ann Pharmacother 2006;40:1814-1821.

77. Kappos L, Barkhof F, Desmet A. The effect of oral temsirolimus on new magnetic resonance imaging scan lesions, brain atrophy, and the number of relapses in multiple sclerosis: results from a randomised, controlled clinical trial. J Neurol 2005;252(supplement 2):S46 (abstract)

78. Sehgal SN. Sirolimus: its discovery, biological properties, and mechanism of action. Transplant Proc 2003;35(supplement 3):7S$14 \mathrm{~S}$.

79. Weinstock-Guttman B, Kinkel RP, Cohen JA, et al. Treatment of fulminant multiple sclerosis with intravenous cyclophosphamide. Neurologist 1997;3:178-185.

80. Confavreux C, Vukusic S. Non-specific immunosuppressants in the treatment of multiple sclerosis. Clin Neurol Neurosurg 2004; 106:263-269. 